\title{
Waste Management in Sri Lanka: Challenges and Opportunities
}

\author{
Lal Mervin Dharmasiri
}

\begin{abstract}
Most of the developing countries face the problem of managing waste properly. In 2012, cities world over, generated 1.3 billion tons of solid waste per year, amounting to a footprint of 1.2 kilograms per person, per day needless to state that with rapid population growth and urbanization, the municipal waste generation is expected to increase to 2.2 billion tons (MT) by 2025. Inadvertently, with the current trends continuing, it is likely to rise from 3.5 MTs to 6 MTs per day with, each person generating around $0.64 \mathrm{~kg}$ waste per day in Sri Lanka with an estimated 4.8 billion MT of waste collected per annum in the country. The main objective of this study is to examine the present situation of solid waste management in Sri Lanka whilst in determining the nature and extent of the problem, thereby identifying the challenges and opportunities towards maintaining a sustainable waste management system in the country. As a result, the study has identified several challenges, of which the absence of waste segregation, poor waste collection mechanisms and the lack of public commitment on waste management, to be some of the underlying causes of the prevailing issue. Thus, the prevailing system on waste collection, transportation and disposal aspects is nevertheless believed to be an issue that needs to be resolved. This is due to the lack of education and awareness amongst the public on waste management, the lack of technical knowledge and the absence of applying 3R principles. In this context, awareness through education and a changing in attitude of the public may be suggested as precautionary methods towards maintaining a sustainable waste management system. The participation of the public is to be quoted as essential, and it should be borne in mind, that this is not a feat that can be accomplished via a limited operation, but rather one which needs to be continued and maintained through ongoing efforts, in keeping the menace at a minimum. Thus, a new model for waste management is required for collection, transportation and the disposal of waste, which should not be harmful to the society nor to the environment. The existing waste management policy of the country should be further developed by considering the concept of zero waste, alternative waste management approaches like waste to energy, sanitary landfills and the acceleration of composting methodology, thereby leading the pathway towards enhanced sustainability.
\end{abstract}

Keywords: Waste management, segregation, zero waste and sustainability. 


\section{Introduction}

Solid Waste Management (SWM) is a major issue in developing economies and priority should be given to overcome this issue, due to the rapid growth of population as well as the increase of waste in developing countries. Although the quantity and quality of solid waste generated by urban areas in developing countries is low in comparison to the Western developed and industrialized countries notable in the west, municipal solid waste management still remains inadequate (Llic and Nikolic, 2016). However, developed countries continuously apply varied approaches, notably composting, land filling and waste to energy processes to overcome issues. In this respect, it is appropriate to examine the strategies that have applied to overcome the issue.

Waste is any subsistence materials derived from 'primary use' or a 'useless defective'. Solid Waste (SW) or 'garbage comprises' of unwanted and discarded materials from houses, street waste, commercial and industrial operations. An increase in the urban population and the rapid change life styles, lead to the generation of solid waste. Generally, solid waste is heterogeneous in nature, for instant refuse of vegetables, food items, paper, plastics, rags, glass and glass. If solid waste is disposed of, on land, in open areas, then it causes a negative impact on the environment, ground water and on health (Mundhe, Jaybhaye \& Dorik, 2014). 'Waste' has value for someone at the same time in which it doesn't for another. If it is possible to convert 'waste' to value, then no more would a 'waste problem' persist in the world.

Most of the countries in the world, in particular, developing countries, face the problem of the proper management of solid waste within their territories. It has been creating different complications by the likes of diseases, unbearable stench, fire hazards, atmospheric and water pollution, aesthetic nuisance, together with social and economic losses. There have been many tragic situations of collapsing of waste dumps in several countries including in Ethiopia and Sri Lanka. Many have pointed out, that, developing countries do not possess the appropriate technology, furthermore, the lack of a proper management and leadership become the major defects of SW management in these countries.

Around the world, the generation of waste is increasing. The amount of waste generated by a country is proportional to its population and the mean living standards of the people (Grossmann et al., 1974). Furthermore, Medina (1997) indicated that the waste generation rates have a close relationship with the income levels of people. In addition, socio economic factors such as persons per dwelling, cultural patterns, education, and personal attitudes also play a role (Nilanthi Bandara, 2008). In 2012, the worlds' cities generated 1.3 billion tons of SW per year, amounting to a footprint of 1.2 kilograms per person per day. With rapid population growth and urbanization, municipal waste generation is expected to rise to 2.2 billion tonnes (BT) by 2025. If the current trends continue, we are likely to go from 3.5 MTs to 6 MTs per day by that point. In South Asia, approximately 70 BT of waste is generated per year, with per capita values ranging from 0.12 to $5.1 \mathrm{~kg}$ per person per day and an average of $0.45 \mathrm{~kg} /$ capita/day (World 
Bank). The continuous indiscriminate disposal of SW is accelerating and is linked to poverty, poor governance, urbanization, population growth, poor standards of living, low level of environmental awareness (Rachel et al., 2009; Ogu, 2000) and the inadequate management of environmental knowledge. However the waste generation rates will more than double, over the next twenty years in low income countries.

Even though human health and safety have become major concerns over waste management in the past, at present, society demands more than expected as in the past. Society expects sustainable waste management, which incorporates feedback loops, is focused on processes, embodies adaptability and diverts wastes from disposal. At a policy level decision making process, environmental consideration has played a major role in this sustainable system. Transitioning from a traditional unsustainable system to a sustainable waste management requires to identify and apply of leverage points which effect change (Jeffrey K. Seadon, 2010). Failure to do so may lead to ill-designed solutions that may not be effective enough to give any productive and sustainable results in waste management. Therefore, a system is required to control the generation, storage, collection, transport or transfer, processing and disposal of solid waste materials in a manner that best addresses the range of public health, conservation, economic, aesthetic, engineering, and other environmental considerations.

\section{Objectives}

The major objective of this paper is to examine the present situation of the SW management in Sri Lanka and to identify the challenges and opportunities in maintaining a sustainable SWM system in Sri Lanka. In addition, alternative strategies will be identified for better SWM in the country.

\section{Waste Issue in Sri Lanka}

Waste has become an issue in the absence of or a weak management system for collection, transporting and disposal. Waste generates mostly at a household level while the rest is generated from industries. The waste problem is not a major issue in rural and sub-urban areas, where, space is available for the disposal of waste unlike in urban areas of the country. It is a significant issue in the urban areas, especially, in the western province of the country.

A survey on waste amounts and Composition Surveys (WACS) conducted by the University of Peradeniya in 2014, revealed that, nearly three fourth of total waste is generated from kitchens. It must be noted that, more than 85 percent of total waste is degradable at the source. Table no 01 shows the composition of waste collection at the point of waste generation in Sri Lanka. However, the figures differ with the study conducted by the Central Environmental Authority (CEA) in 2014. Figure 01 shows the waste composition of Sri Lanka. 
Table 01: Waste amount and composition in Sri Lanka

\begin{tabular}{|l|c|}
\hline Category & \% in wet basis \\
\hline Kitchen waste & 74.6 \\
Garden waste & 4.8 \\
Paper and cardboard & 7.8 \\
Soft plastics & 4.2 \\
Hard plastics & 0.9 \\
Textiles & 1.0 \\
Rubber and leather & 0.4 \\
Metal & 0.9 \\
Glass & 1.7 \\
Ceramics & 0.5 \\
Hazardous wastes & 0.4 \\
E waste & 0.2 \\
Miscellaneous & 2.7 \\
\hline
\end{tabular}

Source; Waste amount and Composition Surveys (WACS), 2014

A similar study conducted by the CEA also pointed out that, the waste composition of the source at the generated point is more or less comparable with the study done by the WACS. According to Fig. 01, about 62 percent of the waste is categorized as bio-degradable, while 7 and 6 percent belong to paper and wooden items which also fall under bio-degradable waste respectively. Altogether three fourth of waste could be categorized as bio-degradable which is capable of being decomposed by the action of microorganisms. This study further identified that, about 6 and 2 percent of waste are polythene \& plastics and glass items which fall under non-degradable waste respectively. Non-degradable waste like polythene and plastic do not break down for several decades, if not centuries, and have a general tendency to poison the ecosystem, as they are petroleum based.

Fig. 01: Waste composition in Sri Lanka

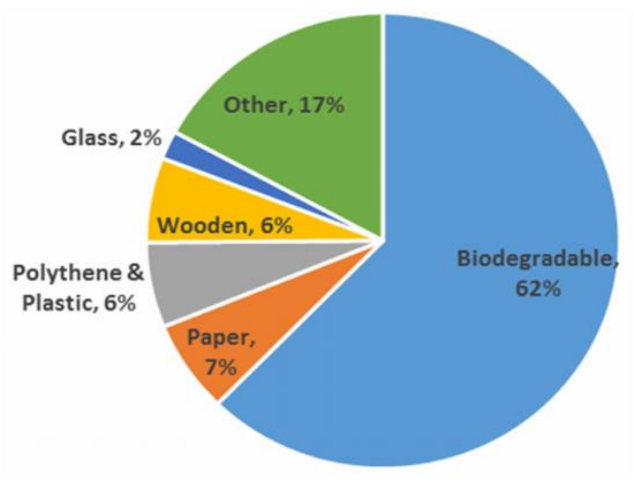

Source; Central Environmental Authority (2014) 
Sri Lanka has 309 local authorities of which 15 are Municipal Councils, 37 are urban councils and 257 are Pradeshiya Sabas manage the SW. Approximately Sri Lanka generates 7,000 MT of solid waste per day. Most of the waste generated in the Colombo Municipal Council which is the largest local government authority in Sri Lanka covers a resident population of over 600,000 . The following table shows waste generation by different local authorities of the country.

Table 02: Daily waste collection

\begin{tabular}{|l|l|}
\hline Provinces & Kg's p/p \\
\hline Colombo Municipal Council & 0.80 \\
Municipal Councils & 0.75 \\
Urban Councils & 0.60 \\
Pradeshiya Sabas & 0.40 \\
\hline Average & 0.64 \\
\hline
\end{tabular}

Source; Central Environmental Authority (2014)

According to Table 02, each person generates about $0.64 \mathrm{~kg}$ 's per day, in Sri Lanka. It is higher in urban areas such as Colombo and Gampaha. Most PS do not collect all the waste generated in their territories but only a part of it is collected. It may be estimated that about 4.8 billion MT of waste is collected per annum in Sri Lanka. However, the actual figure may be higher than the given figure. Table 03, shows the waste collection of the country by provinces.

Table 03: Provincial level waste collection and Disposal sites

\begin{tabular}{|c|c|c|c|c|c|c|}
\hline Provinces & $\begin{array}{r}\text { Generatio } \\
\text { (ton }\end{array}$ & & $\begin{array}{r}\text { Collectio } \\
\text { (ton }\end{array}$ & & $\begin{array}{c}\text { Collection } \\
\text { rates }\end{array}$ & $\begin{array}{c}\text { Number of final } \\
\text { disposal sites }\end{array}$ \\
\hline 1. Northern & 566 & $5 \%$ & 178 & $5 \%$ & $31 \%$ & 16 \\
\hline 2. Eastern & 785 & $7 \%$ & 347 & $10 \%$ & $44 \%$ & 40 \\
\hline 3. North-central & 616 & $6 \%$ & 91 & $3 \%$ & $15 \%$ & 35 \\
\hline 4. North-western & 1,134 & $11 \%$ & 187 & $5 \%$ & $16 \%$ & 45 \\
\hline 5. Central & 1,585 & $15 \%$ & 304 & $9 \%$ & $19 \%$ & 47 \\
\hline 6. Sabaragamuwa & 835 & $8 \%$ & 178 & $5 \%$ & $21 \%$ & 30 \\
\hline 7. Uva & 587 & $6 \%$ & 116 & $3 \%$ & $20 \%$ & 24 \\
\hline 8. Western & 3,502 & $33 \%$ & 1,793 & $52 \%$ & $51 \%$ & 52 \\
\hline 9. Southern & 1,158 & $11 \%$ & 264 & $8 \%$ & $23 \%$ & 60 \\
\hline Total & 10,768 & $100 \%$ & 3,458 & $100 \%$ & $32 \%$ & 349 \\
\hline
\end{tabular}

Table 03, shows the provincial level waste generation, collection and the final disposal sites in Sri Lanka. Accordingly, more than half of the total waste is collected by the Western province. Even though the Western province generates $33 \%$ of the total waste, it collects more than $52 \%$ of the total waste of the 
country. All other provinces contribute less than $10 \%$ each. The Uva province occupies the lowest share of waste generation amounting to $6 \%$ while the Eastern, Central, North central and Southern Provinces produce more than $7 \%$ each of the total waste of the country.

According to Table 03, it was estimated by the University of Moratuwa and the National Solid Waste Management Support Centre (NSWMSC), that 3,458 tons of SW are collected from the island per day. In the Western province, 1,800 tons of SW are collected per day. However, another study conducted by the CEA, revealed that, the total collection of solid waste by local authorities in Sri Lanka is around 2900 tons per day (CEA, 2014). Another study conducted by Hikkaduwa, and others of the University of Moratuwa (2016), titled "Sustainable Approaches to the Municipal Solid Waste Management in Sri Lanka" suggested the collection of solid waste by all local bodies amounts to 3423 MT per day. Approximately $60 \%$ (1663 tones) of the total waste is collected in the Western Province, which is approximately 30 percent of the total population in Sri Lanka.

It is an interesting fact that, at present, a total of 349 sites have been selected for the final disposal of waste by the local government authorities in the country. The waste is being dumped openly at these sites without a systematic manner. It doesn't provide a total solution for waste and also doesn't care about the environmental concerns. However, some of sites have being recycling but it doesn't function in a proper manner.

\section{The Responsibilities of Waste Management in Sri Lanka}

The responsibility of waste collection from its generated point to disposal sites are vested in local government authorizes such as Pradeshiya Sabha (PS), Town Councils (TC) and Municipal councils (MC). In Sri Lanka 111 local authorities function through the elected members of the particular area. These authorities are responsible for the collection, transportation and the disposal of solid waste in a proper manner. The following table shows the range of waste collected by a number of local authorities. 
Table 04: Different ranges of daily SW collection [tones/day]

\begin{tabular}{|c|c|}
\hline Ranges [Tones/ Day] & Number of local authorities \\
\hline Up to 1 & 111 \\
$1-2$ & 48 \\
$2-5$ & 76 \\
$5-10$ & 26 \\
$10-20$ & 23 \\
$20-50$ & 19 \\
$50-100$ & 5 \\
$110-150$ & 2 \\
$>150$ & 1 \\
\hline Total number of local authorities & 111 \\
\hline
\end{tabular}

Source; Central Environmental Authority (2014)

It is clearly indicated in the Municipal Council Ordinance in 1947, the Urban Council Ordinance in 1939 and the PS Act in 1987. In addition, all disposal activities should be handled according to the National Environment Act No 47. However, several ministries are also responsible for waste management in the country. They are the local government and provincial councils, Mahaweli Development and Environment, and Megapolis and Western Development. The Western province has a separate arm to handle solid waste within their province. Apart from the Ministries, several authorities like the Central Environmental Authority and the Urban Development Authority are also responsible for policy making, providing training, and equipment to the local government authorities.

Furthermore, the relevant ministry of the provincial councils has the overall responsibility for the enforcement of rules and regulations in the provinces. Furthermore, they are also responsible to regulate the operation of and the transportation and processing of Municipal Solid Waste together with the management of final waste disposal facilities of waste without being a nuisance to the general public and/or to the flora and fauna of the Province.

Several waste management steps have already been identified by the Waste Management Authority, of the Western Provincial Council (See; Municipal Solid Waste Management Rules-2005) for the better handling of and the cleaning of the environment of their area. They are as follows; 
- Properly Manage the SW at Source i.e. segregation, reduction, reusing and recycling and prohibiting the dumping of solid waste on streets or public places and open burning of wastes are being considered.

- Proper Collection/Acceptance of MSW from the Source of Generation.

- Cleaning of Streets and Public Places.

- Abolition of Open MSW Storage Bins. The abolishing of open storage waste bins from main roads, public places and the introducing of close type of appropriate waste receptacles.

- Improving a System for Mass Transportation of MSW. Under which the prohibition of waste transportation in open vehicles and the optimizing of the efficiency of the vehicle usage for waste transportation are considered.

- Treating the Collected MSW as a "Resource". Encouraging the recovering of resources from collected MSW through the re-using of MSW for composting, Power generation, and production of biogas, bio-fuel, electricity, bio-gas and the use of state of- the- art technologies together with re-cycling.

- Improving a System for the Final Disposal of MSW. The establishing of engineered and/or sanitary landfills and the use of state- of- the- art technology for such events at a zonal and/or regional level.

\section{The Challenges of Waste Management in Sri Lanka}

One of the biggest problems in Sri Lanka is to manage the management of SW in a sustainable manner. The prevailing system of waste collection, transportation and disposal are yet to be resolved. It is possible to identify these issues which are discussed below as the challenges of WM in Sri Lanka.

Waste segregation: Segregation is the systematic process that waste is separated into different types. It can be done manually at a household level or mechanically. Basically, waste could be divided as dry and wet waste. Then, it could be further divided into solid waste, bio-degradable, non-biodegradable, toxic waste and recyclable waste. Thus far, we do not have a proper system or the proper practice of segregation at the generation or collection points. Every individual has the responsibility to practice such a segregation system. Nevertheless, only a few are practicing it.

Waste collection and transport: Waste collection, storage and transporting of waste are essential elements of any WM system and can be major challenges in towns and cities. As mentioned above, the collection of SW is done by the PS, TC and MCs. All 111 local bodies have been collecting waste to keep their territories clean. The Waste Management Authority (WMA) of the Western Province is responsible for more than $60 \%$ of the total waste collection of the country. The Collection of waste from house to house and entire industries, commercial areas 
and public areas have to be transported and unloaded either into processing sites or sanitary landfills by the above authorities. However, it has not been done in a proper and sustainable manner.

Waste disposal: The absence of a proper arrangement for the disposal of garbage in towns and cities create many more challenges in the face of financial, technical and administrative incapacities of the relevant local bodies. Be it from an individual, to institutions or Ministries related to WM should play a role in this regard. A few sanitary landfills and organic composite yards are available for the sustainable disposal of garbage. Unfortunately at present, solid waste is collected in a mixed scale and disposed of in environmentally sensitive areas, such as, abundant arable land, marshy land, forests, wild life habitats, near water bodies, isolated hilly areas and so on. Most of the local bodies collect garbage and dump it at open lands which create many problems.

Pollution: Different types of pollution arises when the waste collected in dumping sites keeps rotting, spreading odour, contributing to water and soil pollution, and numerous health related problems in addition to the aesthetic pollution which is caused in the surrounding areas. Most of the dumping sites are located in open spaces. They are burnt sometimes and this causes the emission of toxic gases like carbon dioxide and carbon monoxide which create health issues.

Garbage from the household and other sources falls into rivers and water bodies. It makes the water of the water bodies polluted. The blocking of the drainage system in towns and cities create breeding sites for mosquitoes and other vectors which spread diseases such as Malaria, Dengue, Filarial and contributing to numerous other health problems. In addition, the improper spreading of garbage from place to place and dumping it thus, could increase the population of flies and rats which create many more health issues.

Increasing garbage at households, outside and/ or water bodies have become a serious problem to the air, water and soil. Accordingly, the physical properties of the soil could change, and thereby the growth of plants and other factors affecting soil nutrition adversely.

An inappropriate and unsustainable dumping of waste would also destroy or reduce the worth of the aesthetic value and the scenery and beauty of the surrounding areas.

Institutional set-up: Several authorities i.e. Local government authorities, the Waste Management Authority, the Central Environment Authority, the Ministry of Environment, the Ministry of Megapolis and Western Development have been dealing with the SW management in the country. Additionally, several projects were also set up to support and to manage the SW 
issue in Sri Lanka. The lack of coordination between institutions, the lack of Institutional capability with technical expertise and the lack of adequate funds are some issues in the system at large.

Public commitment: The literacy rate of Sri Lankans is much higher than that of other developing countries. It means that literate people should work in a systematic manner in relation to WM. At the onset, at the school level all students were given training in the systematic practice of WM in their surrounding environment. Unfortunately, when they became adults, most of them do not follow the principles of WM. It has become a serious issue in the country.

Political arena: There is a lack of commitment in most of the parties that are involved in WM in the country. Many obstacles arising when the ruling party of a particular local body work on the waste issue. Simultaneously, the same can be applied in a different way which arises when the opposition takes over in the same local body. Ultimately, the issues of WM remain stagnate in most of the local bodies.

The challenges therein would be able to be overcome with the commitment of the collaborative attendance of the public and private sector, government interference and the mindset change of the people of the country. The following opportunities may be useful to overcome the identified challenges of WM in Sri Lanka.

\section{Opportunities of Waste Management of Sri Lanka}

Education and awareness: Knowledge from education and awareness has been seen as a key factor affecting environmental action. It is a vital fact that, environmental knowledge plays a significant role in changing the environmental activities and human behavior. A change in habits, behavior and the participation of the people on 'what do you/ people think about waste' is a significantly important aspect of solid WM. As all know, most information and practices about WM start at school and influence their households. The WM process at a school level is focused on keeping the environment clean and recycling the bio-degradable items. This process would help increase awareness and attitudes towards solid WM among children and their parents.

Improvement of technical knowledge: The adoption and transfer of the technologies of WM either from developed countries to local level authorities and people who are responsible for WM at the grass root level would be immensely beneficial for better practice. Technical aspects for a WM would have to be taken into account, in many points, from bottom to top, for planning and the implementation of different activities. The provisions of a better technical knowledge would directly support sustainable WM practices in the country. 
Application of 3R principles: The principles of 3R i.e. reduce, reuse and recycle can be applied in an acceptable manner to cut down on the amount of waste people throw away. The simple logic behind the principle is easy to understand, if there is less waste, then there is less waste to recycle or reuse. Any items that can be used again for another purpose or in a different way is called 'reuse'. People can reuse most items such as plastic bags, furniture, toys and repair some broken items that they used. On the other hand, they can sell or give it to others for charity. Recycling is a process which will be transformed again into raw materials that could be shaped into a new product. All materials could be recycled or transformed except for a few items in the world. About $38 \%$ of the waste such as glass, paper, wood items and so on could be transformed into recyclable items in Sri Lanka.

Waste segregation: Waste segregation is essential as the amount of waste being generated causes many problems. Most of the bio-degradable waste could be transformed into fertilizers and only a small proportion of the waste has to be discarded. Unfortunately, the bulk of waste is not being segregated yet by the responsible people and the quantity of waste would be much higher. In particular, household waste can be separated into different baskets for the different categories of waste such as degradable and non-degradable which should be disposed separately.

Attitudinal change: Waste could be identified as 'two sides of a coin', which highlights the idea of the environment as a gift and a responsibility. People were open-minded about the environmental impact on improper waste management. Everybody should understand that waste is from nobody, it belongs to everybody. Therefore, everybody has a responsibility to manage waste in a proper manner.

Independent authority: At present, there are many institutions which deal with WM in Sri Lanka. Therefore, a strong and independent authority is required to regulate WM if WM is to improve and be kept in a sustainable manner in the country. The absence of clear regulation and enforcement will make deter in a timely and in a proper manner. The WM sector needs to include attractive and profitable business models with clear performance requirements imposed, with financial penalties applied when WM services are not working effectively.

Adequate funds: Finance for WM authorities and funding for other WM activities should be raised through Waste Management Tax (WMT) which comes through the Polluter Pay Principle (PPP). According to the policy, tax amount should be paid by all the polluters for covering the expenditure on keeping the environment clean and fair. An average WMT of 1 Rupee per transaction of non-degradable wrapped items sold by merchants to buyers would generate a 
huge amount of money and the collected funds could be used for proper waste management in Sri Lanka. In addition, the PPT policy could be applied to the person who violates the waste management system of a particular city.

Alternative strategies: Several alternative strategies are being implemented by the respective authority in the country. Zero waste, Waste to Energy, sanitary landfills and large scale composting. At present there are several landfills in the process of constructed at Aruwakkaru, Keeramale, Medirigiriya and Keerakkulama. In addition, two waste to energy project plants of 10 megawatts each, to incinerate, commenced in the Western province. The Ministry of local government is also establishing several mega composting machines in selected districts.

\section{Alternative Strategies for better WM practice}

It is an important fact that the education on WM should be further expanded for all the sectors which start at the kindergarten schools. The role and responsibilities of WM of each individual should be communicated and instructed in a proper way. It may be one way of forming responsible citizens who manage waste as resources whilst applying $3 \mathrm{R}$ principles and creating a zero waste or waste less society in the future.

It is a vital requirement that WM must involve waste segregation at sources such as households, market or industries to allow more efficient value extraction and recycling. It should be separated into dry/ wet or bio degradable/ non-degradable etc. Then, the waste would have significant benefits for waste collectors and the people who are involved in the WM field. Innovative and practical waste management regulations could be imposed. The WM sector needs to include attractive and profitable models with financial penalties from polluters and WM discipline breakers. Then, the WM services include collection, transport and disposal which will be sustained effectively and efficiently.

Short term and long term comprehensive WM planning requires to overcome WM issues in the country. Private sector involvement should be strengthened for most of WM activities. Local level provincial councils and the Ministry of Local Government could monitor and evaluate the WM practices. To achieve the targets, training and capacity building is required from the grass root to the top level people who are engaged in WM.

\section{Conclusion and recommendations}

The quantity of generated waste is continuously increasing due to the growing population and increase in development. The Modern way of life has led to serious waste problems in the country. Easy products require more packaging and the habits of the people are also associated with generating larger quantities of waste, discarded wrappers from inevitable fast foods. Modern day waste contains a higher proportion of non-degradable materials which have caused an acute waste issue. The problem has further 
worsened due to the extensive use of plastic products such as plastic bottles. Despite the huge amounts of waste produced, the standards of waste management in the country are still poor. These include outdated and poor management of waste and, the inefficient handling, collection, transportation, disposal of hospital wastes and hazardous waste together with the dumping of wastes. Waste at the roadside, drains blocked up with garbage and plastic items and rivers filled with filthy garbage indicate that, solid waste is a major environmental problem in Sri Lanka.

This situation has diminished the environmental quality to sustain life. If the present rate of solid-waste production goes on without a proper waste management system, there will be significant negative impacts on the quality of the environment. In addition, the inadequate awareness and knowledge about solid waste management issues, and the ignorance of the effect of improper SWM has definitely worsened the problem.

Sri Lanka needs a long-term goal to establish a sustainable and effective SWM that are cost effective, economically viable and environmentally sound. Strategies that have been recommended for waste minimization are part of the waste management hierarchy and involve 3R principles such as reduce, reuse and recycle.

The situation could be managed in a sustainable manner through several implications. Providing awareness from schools up to the higher education level in different scales and standards would be ideal. It may be able to change the attitude and awareness of the masses through formal and informal education.

The appropriate technical knowledge and equipment should be provided to the local government institutes. Technical training is also an essential component for the people who practically engage in SWM at the field. WM requires not only technological knowledge but also public participation, consultation and stakeholder mutual understanding and dialogue on activities.

Waste segregation is a vital part of SWM and attention should be paid to impart all stakeholders to follow the principles of waste segregation. It should be practiced from the household level to the top level institutions of the country.

It is necessary to establish an apex independent institution to regulate SWM in the country. The institution should control all other institutions which deal with SWM. The institution could apply a good market model for managing SW in a profitable manner. The Legal framework should also be established to raise the required additional funds for the efficient management of the institution and also the PPP would be an ideal concept to strengthen SWM. 
The available WM policy of the country should be further developed by considering the concept of zero waste, with alternative WM approaches like waste to energy, sanitary landfills and accelerating composting methodology which is required to manage the waste in a sustainable manner.

\section{References}

Central Environmental Authority (2014) 'Present status of solid waste management and challengers for change' [Online Web: Accessed on 20th April, 2019], http://www.cea.lk/web/images/REEB/Present_Status_of_SWM_2.pdf

Daniel Hoornweg and Perinaz Bhada-Tata WHAT A WASTE: A Global Review of Solid Waste Management. The World Bank. March 2012, No. 15, [Online Web: Accessed on 13th March, 2019], https://openknowledge.worldbank.org/handle/10986/17388

Data Collection Survey on Solid Waste Management in Democratic Socialist Republic of Sri Lanka Final Report. Japan International Cooperation Agency (JICA) Kokusai Kogyo Co., Ltd. [Online Web: Accessed on 2nd March, 2019], http://open_jicareport.jica.go.jp/pdf/12250213.pdf

Hikkaduwa, H.N.; Gunawardana, KW; Halwatura, RU; Hee, H "Sustainable Approaches to the Municipal Solid Waste Management in Sri Lanka" [Online Web: Accessed on 20th March, 2019], URI: http://dl.lib.mrt.ac.Ik/handle/123/11569

Grossmann, D.,Hudson, J. F., \& Marks, D. H. (1974). Waste generation models for solid waste collection. Journal of the Environmental Engineering Division, 100, 1219-1230.

Jeffrey K. Seadon, (2010), Sustainable waste management systems, November Journal of Cleaner Production 18(16):1639-1651, [online Accessed on 12nd November, 2019], https://www.researchgate.net/publication/245168221 Sustainable waste management systems

Llic, M., and M. Nikolic. (2016), Waste management benchmarking: A case study of Serbia. Habitat Int. 53:453460. doi: 10.1016/j.habitatint [online Accessed on 02nd November, 2019], https://www.tandfonline.com/doi/full/10.1080/10962247.2016.1229700

Medina, M. (1997). The effect of income on municipal solid waste generation rates for countries of varying levels of economic development: A model. Journal of Resource Management and Technology, 24(3), 149-155, 1997.

Mundhe, Jaybhaye \& Dorik (2014), Assessment of Municipal Solid Waste Management of Pune City using Geospatial Tools, International Journal of Computer Applications (0975 - 8887) Volume 100- No.10, August 2014

Nilanthi J.G.J. Bandara ,(2008), 'Municipal Solid Waste Management - The Sri Lankan Case' Paper Presented at Conference on Developments in Forestry and Environment Management in Sri Lanka. [Online Web: Accessed on 20th March, 2019], http://journals.sjp.ac.lk/index.php/fesympo/article/view/21/17

Ogu, V.I., (2000), Private sector participation and municipal waste management in Benin City, Nigeria. Environ. Urban. 12 (2), 103-117.

Rachel, O.A., Komine, H., Yasuhara, K., \& Murakami, S., (2009), Municipal solid waste management in developed and developing countries-Japan and Nigeria as case studies. [Online Web: Accessed on 03th March, 2019], http://wwwgeo.civil.ibaraki.ac.jp/komine/mypapers/JGSPaper/2009/JGS2009(973)Rachel.pdf

Waste Amount and Composition Surveys (WACS) implemented in the Central and Southern Provinces of Sri Lanka, SATREPS report (May 2014)

Waste Management Authority (Western Province) (2015), Municipal Solid Waste Management Rules- 2005, Joint programme of the Government of Sri Lanka, Western Provincial Council \& USAID/USAEP

World Bank. Solid Waste management [Online Web: Accessed on 12th May, 2019], http://www.worldbank.org/en/topic/urbandevelopment/brief/solid-waste-management 